KLEINE TEXTE FÜR THEOLOGISCHE UND PHILOLOGISCHE VORLESUNGEN UND ÜBUNGEN

HERAUSGEGEBEN VON HANS LIETZMANN

$50 / 51$

\title{
URKUNDEN
}

Z U R

\section{GESCHICHTE DES BAUERNKRIEGES UND DER WIEDERTÄUFER}

HERAUSGEGEBEN

VON

DR. H. BÖHMER

o. PROFESSOR IN BONN

BON N

A. MARCUS UND E. WEBER'S VERLAG

1910 


\section{Handbuch zum Neuen Testament}

in Verbindung mit

H. Gressmann, W. Heitmtller, E. Klostermann, F. Niebergall, E. Preuschen, I. Radermacher, F. Schlosser, P. Wendland, I. Windisch herausgegeben von

Hans Lietzmann

Vom ,Handbrch zum Nenen Testament" gelangten bis Dezember 190915 Lieferungen zur Ausgabe. Davon bilden Lieferung 2, 7, 8, 9, 10, 12 und 14 den $\nabla$. Band, die

Praktische Auslegung des Neuen Testaments ftir Prediger und Religionslehrer.

Einzeln M. I1.20. Geburiden M. I3.-.

Bei Subskription auf das ganze Handbuch Pr. M. 10.-. Geb. M. I2.-. Aus den übrigen Bänden sind bis jetzt erschienen:

Band I, 2: Die hellenistisch-römische Krultur in ihren Beziehungen zu Judentum und Christentum. Von P. W end land. Mit 5 Abbild. i. Text u. 12 Tafln. Lex 8. Einzeln M. 5.- Gebd. M. 7.- Subskr.-Preis M. 4.50. (Lieferung 3 u. 4.)

Band II. Die Evangelien. Bogen I-10: Markus. Unt. Mitwkg. von $\mathrm{H}$ ugo $\mathrm{Gressmann}$ erklärt v. Erich Klos termann. Lex 8 . Einzeln M. 2.85. Gbd. M. 3.80. Subskr.-Preis M. 2.56. (Lieferung 6. Doppel-Lieferg.)

Band II, 1, Bogen $1 \mathrm{I}-24$ : Matthäus. Unt. Mitwirkung von $\mathrm{H}$ ugo Gressmann erklärt von Erich Klostermann. Lex 8. Einzeln M. 4.-. Gbd. M. 5.-. Subskr.-Pr. M. 3.62 (Lieferung I3 und 15.)

Band III. "Briefe des A postels Paulus « Bogen $\mathrm{I}-5$ : An die Römer. Erklärt von Hans Lietzmann. Lex 8. Einzeln M. 1.50. Gbd. M. 2.50. Subskr.-Preis M. 1.35. (Lieferung I.)

Band III. Briefe des Apostels Paulus Bogen 6-11 und 12-15: An die Korinther I und Ir. Erklärt von $H$ ans Liet $z$ mann. Lex. 8. Einzeln M. 2.80. Gbd. M. 3.80. Subskr.-Preis M. 2.52. (Lieferung 5 u. II.) Galaterbrief erscheint Februar I9Io.

Prospekte und Textproben stehen zur Verfügung.

tbersicht ther das Sammelwerk:

Band I: I Grammatik des neutestamentlichen Griechisch von L. R ad er macher. 2. Die hellenistisch-römische Kultur in ihren Beziehungen za Judentum und Christentum von P. Wendland. (Erschienen. Einzelpreis M. 5.-. Gebd. M. 7.-.) 3. Die urchristlichen Literaturformen von $P$. W end land.

Band II: I. Die Synoptiker unter Mitwirkung von H. Gressmann, erklärt von E. Klostermann. Erschienen Markus: Lieferung 6. Matthäus: I. Hälfte (Lieferung 13), 2. Hälfte (Lieferung 15) 2. Johannesevangelium, erklärt von E. Klostermann.

Band III: I. Die vier paulinischen Hauptbriefe erklärt von H. Lietz mann. Erschienen Römerbrief, I. und Ir. Korintherbrief : Lfg. I, 5 u. I I. Galaterbrief unter der Presse. 2. Die neun übrigen paulinischen Briefe erklärt von E. Klostermann u. H. Lietzmann.

Band IV : I. Die Apostelgeschichte, erklärt von E. Preuschen; 2. Ka. tholische Briefe, erklärt von $\mathrm{H}$. W in d is ch; 3. Hebräerbrief, erklärt von H. Schlosser; 4. Apokalypse, erklärt von W. Heitmüller.

Band V: Praktische Auslegung des Neuen Testaments für Prediger und Religionslehrer v. F. Niebergall. Einzelpreis M. I I.20. Gbạ. M. 13.-. 